\title{
Perishable Inventory Challenges
}

\author{
Cecilie M. Damgaard, Vivi T. Nguyen, Hans-Henrik Hvolby ${ }^{*}$, \\ and Kenn Steger-Jensen
}
Centre for Logistics, Department of Mechanical and Manufacturing Engineering, Aalborg University, Denmark
hhh@celog. dk

\begin{abstract}
This paper is based on an exploratory research project into perishable inventory challenges in the retail industry. This paper investigates how inventory control of perishable items is managed and identifies the perishable inventory challenges. The paper includes a review of relevant literature and identification of models dealing with perishable inventory control. The paper is based on a case study in the retail industry in Denmark about how the current procedures are operating in the retail supply chain. Based on the case study and literature review it is found that product quality deterioration and the aftercare of the items in the retail stores are two important parameters in perishable inventories. Furthermore, the length of periods as well as the total cost and profit margin function of the inventory control models are does not often fit reality. Therefore there is a need for further research into models dealing with these parameters.
\end{abstract}

Keywords: Perishability, Inventory Control, Retail, Fresh Food Supply Chains.

\section{Introduction}

Product perishability is of major concern in many industrial sectors. Fresh food, blood products, meat, chemicals, composite materials and pharmaceuticals are all examples of perishable products that can deteriorate and become unusable after some finite time $[2 ; 8 ; 15]$. Other industries supplying services also deal with variety of perishable products such as airfares, hotels and concerts [1]. This complex issue supports the rationale for investigation into perishable inventory control in several industries as well as most countries.

Handlings of perishable inventories occur naturally in many practical situations. The perishable products are naturally managed in practice, as the length of the lifetime of the product defines the maximum length between the order frequency [15]. However, not many inventory control models take perishability of the products into account which is a weakness in these models. Most inventory control models assume that stock items can be stored indefinitely to meet future demands as in the case of the EOQ model. However, when dealing with perishables, the product lifetime must be taken into account in inventory models. Perishable inventory is a challenge for

\footnotetext{
* Corresponding author. 
companies both from a managerial and an operational point of view. The retail industry in Denmark deals with perishable inventory on a daily basis. The challenges arise when unsold perishable items approach their expiration date. Then management has to decide whether or not to sell the items at a lower price than expected or simply consider the remaining inventory as waste. To investigate these issues a single case study has been conducted in the Danish retail industry.

When the inventory holds the same product variant, but with different expiration dates, then the challenge occurs since the items have different quality level due to the different length of remaining shelf life. Decisions can be difficult, as the remaining items needs to be taken into account, when making replenishments. In order to ensure a higher profit, when dealing with perishable items, the shelf life must be taken into account. According to Gürler [8] a significant reduction in the cost function can be obtained by explicitly taking into account the randomness of the shelf life and the system costs differ drastically among various shelf life distributions, which imply that a precise estimation of the shelf life distribution is desirable.

This exploratory research is based on the belief that better knowledge about the products' remaining shelf life and use of this information in the inventory control can help retailer managers with better planning and less use of manual resources. Therefore, the study of the effects of a product's lifecycle are important to identify for managers and researchers alike.

In the following, an overview of the existing inventory control for perishable items is presented as well as a discussion of the ordering strategies for retailers. The paper ends up with an identification of important parameters in perishable inventories, which needs to be taken into account in perishable inventory control models.

\section{Perishable Inventory Models}

The literature of perishable inventory is generally divided into two; perishable inventory theory and the dynamic nature of the perishables. Together the literature discusses the impact and consequences perishable items have on inventory control models. The interest in the research literature about perishable inventory have increased over the last two decades [8], where the Nahmias [15] presented an extensive review of the relevant literature on lot-sizing problem with deteriorating and perishable items. Later several authors have contributed to the development of a number of inventory models for deteriorating items [9].

Nahmias [14] defined characteristics of a perishable item with a limited shelf life and introduced ways of using the traditional models to account for items having a limited lifetime. One way is by defining the periods according to the length of the items lifetime. An example is by using the simple EOQ model; the annual demand in the general EOQ is set to be the expected demand over a period equal to the items lifetime. This ensures that no units expire [15].

Nahmias [14] also contributed to the literature as one of the first to derive and evaluate optimal order policies for obsolescent products with shelf life greater than 
two periods. This was followed by an in-depth understanding of the quality deterioration of perishable items [8; 5; 4]. Pierskalla and Roach [17] addresses that issuing the oldest item first, through the FIFO principle, is the optimal policy from the perspective of the retailer, when the objective is to minimise total inventory holding cost (and waste). However, in practice this is not always controllable by retailers. Often, customers selects the latest delivered products first (especially fresh-food) thus the LIFO principle is a more realistic assumption [5].

Some authors dealing with perishable inventories suggest use of the newsvendor model, others suggest use of periodical reviews based on the items lifetime [14].Most inventory models for perishable items are based on the traditional models, which are often driven by a cost reduction focus. However, few models have a profit optimisation focus, where the price of the perishable product is an explicitly variable in the model [5]. Another model focusing on profit optimisation is the newsvendor model, which defines the possible sales opportunities and loses The objective function of the inventory control model has an impact on the outcome but also an impact on the operational level in the company. Depending on the domain of industry and the ordering strategy, there is a need to consider the objective function. A segmented overview of traditional inventory control policies is illustrated in figure 1.

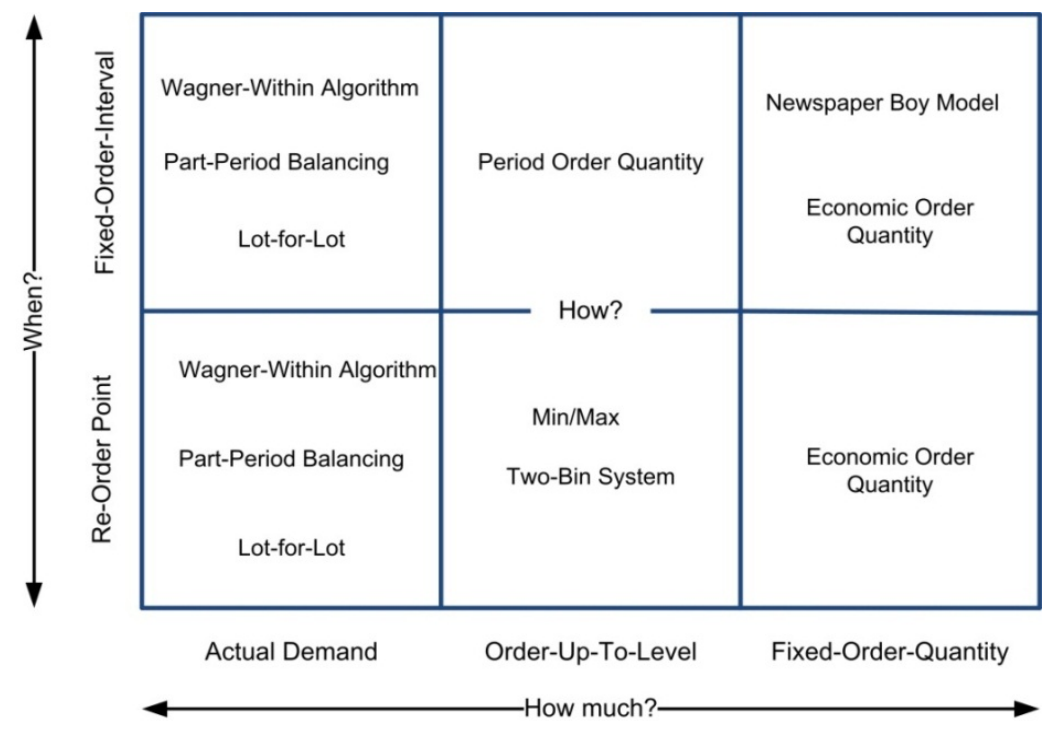

Fig. 1. A segmented overview of traditional inventory control policies

\section{$3 \quad$ Ordering Strategy}

Beside the elements of the traditional inventory models, some element has to be acknowledged when dealing with perishables. As perishable inventories undergo change in storage it may in time become partially or entirely unfit for consumption. The life- 
time of a product is often measured in days which defines when the products become unacceptable for consumption [4]. Dealing with perishable inventories has a large impact on the inventory control model. Most inventory models assume that stock items can be stored indefinitely to meet future demands, which is not the case with perishable items [14]. Thus, the assumption of infinite shelf life for the inventoried items has originated a considerable amount of criticism to the EOQ model in the inventory lot-sizing literature [9].

A more diversified picture of strategies, which also affect the inventories, is seen when comparing high-end stores and discount stores. A general picture seems to be that high-end stores aim at customer service in terms of a broad assortment and high product availability at the expense of higher inventory investments, while discount stores aim for a limited assortment and low inventory at the expense of possible outof-stock situations. This case study is based on both high-end stores and discount stores.

From the case study it was found that the decision-making regarding the products aftercare is based on the individual manager's perception of the characteristics of the perishable items and how the highest profit margin can be achieved.

Another challenge found in the case study is that the retailers are not able to use point of sales (POS) data to identify products that are about to reach their expiration date. Instead, many manual resources are used to identify the products, which have reached or almost reached the expiration date. This is due to the fact that the barcode used for POS identification at checkouts does not include the products expiration date. Several major challenges exist for establishing the input for calculating the order quantity:

- How to estimate the current inventory level when having products of varying lifetime stored?

- How to set the sales price for products with more or less reduced lifetime?

- How the remaining demand is affected if products with reduced lifetime are sold at a reduced price (also titled cannibalisation ${ }^{1}$ )?

\subsection{Demand-Price Relation}

Ferguson and Koenigsberg [5] present the mathematical function, that if the relation between demand-price is known for a given product, then the desired sales price for new and old products can be found through a linear function, based on the market potential, order quantity of new products, and inventory level of old products. If old products are sold at a discount price they might capture the entire demand share and the retailer will obtain a smaller profit margin of the product but avoid waste. Thus,

\footnotetext{
${ }^{1}$ Cannibalization is the term used when old products sold at a reduced price will lead to a reduced sale of new products [3]. If the old products are sufficiently attractive the customers may find it beneficial enough to buy the old products rather than the new products. The term originates from the literature of marketing strategy, which describe that competition among product types lead to a reduction of sales volume, sales revenue, or market share. Cannibalization can also occur when the producer or their competitors introduce new products.
} 
the expected profit margin of a single product has to be revised by the retailer in order to recalculate the total profit. Desai [3] has further investigated the consequences of the competition of the products caused by cannibalisation. It can be interpreted from Desai's findings, that by having the right price strategy in the product differentiation of old and new products, they become substitutes of each other instead of competing for the same demand.

\subsection{Quality Categorisation}

The contributions which have value for the literature of perishable inventory control, are the in-depth understandings of the quality deterioration of perishable items $[4 ; 5]$. The quality of the product is a function of product life time, however there is a difference in the perception of the quality from the customer view and the retail store view. The perception of the quality is a reflection of the price the customers are willing to pay where the retail stores are speculating on determining the price. The retail stores are always seeking to mark the price as high as possible in order to gain a higher profit margin. From a retailer's point of view this is done by speculating about the customers' behaviour and perception of the quality whereas the customers consider the quality of the products from the value for money perspective.

The categorisation of the quality level is inspired by Ferguson and Koenigsberg [5], Talluri and Ryzin [19], and the retail case study. As illustrated below in figure 2 the quality level can be categorised into three main types based on the characteristics of the products, as it is believed to be representative for all product types.

Type 1

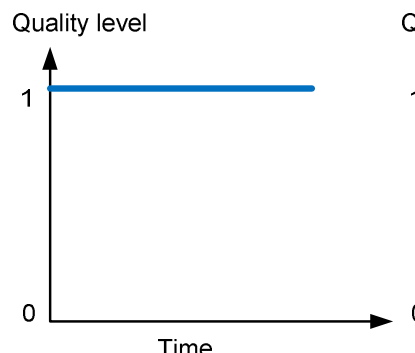

Time
Type 2

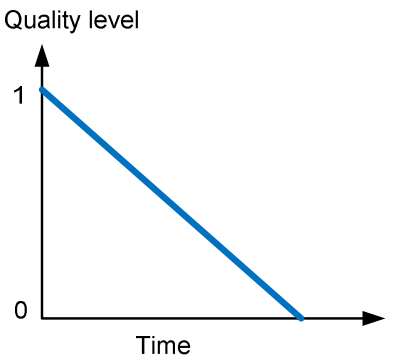

Type 3

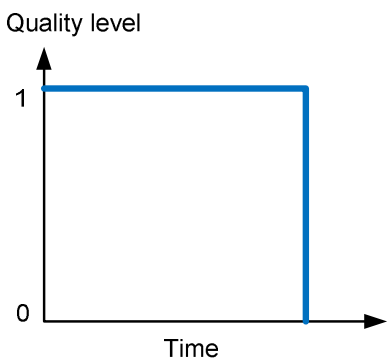

Fig. 2. Three basic quality level categorisations inspired by [5;19]

In the first type of quality, the product maintains the same quality level, but never reaches a value of zero over time. However, the rapid changes in the market, such as season and trends, have an influence on the customers' perception of quality level of the products. Therefore, the end of the product shelf life will often be determined by the customer's perception. Type one is not affected by the time dimension and can therefore be managed from the traditional inventory models. 
The second type of quality level is a product, where the quality level degrades continuously over time and at the end of the shelf life has reached the value of zero. Often, the product within this type of quality does not reach a value of zero before a replenishment of new products arrives [5]. Thus, a single product type in the retail stores can have different levels of quality on the shelves. Therefore, product quality is an important parameter in the inventory control for type two products.

The third type of quality level is where the products maintain the same quality level over time but become unusable after the expiration date. The customers' perception of quality does not decrease over time, but has no value for the customers, when the product expires at the given date. As the product can only be used before a given date, customers prefer to purchase closer to the date in order to ensure that the product will be utilised. Thus, many firms providing these product services set multiple prices for the products depending on the demand, number of remaining product, and, remaining time before expiration date. The purpose of this is to enhance the demand for purchasing in advance, in order to ensure the highest possible profit margin. Furthermore, it is also an approach the companies take in order to reduce the risk of having unsold products left. $[1 ; 5]$.

\subsection{Parameters in Perishable Inventory Control}

Dealing with the nature of perishability in inventory control, the quality deterioration of the perishable products has to be taken into consideration together with the unsold inventory from previous periods. The reason is that the different quality levels have different values, and therefore cannot be considered the same, since the products with the lowest quality will have a lower attractiveness for some customers. Some companies meet the different quality levels by differentiating on sales prices, though this affects the profit margin. If the inventory control objective function is based in profit maximisation, then it might be beneficial to incorporate the different product qualities in the development of the inventory control model.

A major challenge is the aftercare of the unsold perishable products, as this has a great impact on the ordering policy, when finding the optimal order quantity. Many retailers, including the case company, do not have a predefined strategic decision making process describing what to do with the unsold inventory before the perishable products have almost or reached the expiration date. The consequences are; the companies do not optimize the profit gain from the potential market. The "mark down" price decision with the purpose of minimizing the loss of investment often fails due to the timing.

In the development of a perishable inventory control model some important parameters, has to be evaluated. The latter contribution is the identification of the elements: 1) demand, 2) periods, 3) quality deterioration of the perishable item, 4) the aftercare of the items including price of the new and the old perishable items and 5) total cost and profit margin function. 


\section{Conclusion and Further Work}

The paper identifies relevant parameters which will serve as input to the further development within perishable inventory control models. They are 1) demand, 2) periods, 3) quality deterioration of the perishable item, 4) the aftercare of the items including price of the new and the old perishable items and 5) total cost and profit margin function. Furthermore, it provides a deeper understanding of the nature of perishables in the retail industry together with the identification of the importance of how the aftercare of items is conducted. It is important to acknowledge the importance of product quality and the parameter must therefore also be considered in the inventory model. Furthermore, when dealing with perishable inventory control, the pricing of products has to be taken into account. Lastly, a better aftercare of items close to expiration date will help reduce investments in inventory and ensure a better profit margin.

Further work will aim at developing a mixed model that is able to handle the time dimension of existing inventory. The case study showed that the existing models do not consider that companies have the same products with different lifetime left. Further, the options and outcome of improved information sharing in supply chains will be studied $[6 ; 16 ; 18]$.

Acknowledgement. The authors of this paper graciously acknowledge the funding provided by NordForsk for the LogiNord "Fresh Food Supply Chain" project and Christopher Martin for his valuable comments in the paper writing process.

\section{References}

1. Belobaba, P., Odoni, A., Barnhart, C.: The Global Airline Industry. Wiley (2009)

2. Chakravarthy, S.R., Daniel, J.K.: A Markovian inventory system with random shelf time and back. Computers \& Industrial Engineering 47, 315-337 (2004)

3. Desai, P.S.: Quality Segmentation in Spatial Markets. When Does Cannibalisation Affect Product Line Design. INFORMS Marketing Science 20(3) (2001)

4. Donselaar, K.V.: Inventory Control of Perishables in Supermarkets. International Journal of Production Economics 104(2), 462-472 (2006)

5. Ferguson, M.E., Koenigsberg, O.: How Should a Firm Manage Deteriorating Inventory? Production and Operations Management Society 16(3), 306-321 (2007)

6. Ferguson, M., Ketzenberg, M.: Information Sharing to Improve Retail Product Freshness of Perishables. Production and Operations Management 15(1), 57-73 (2006)

7. Gray, M.: Value: Operations Research and the new health care paradigm. Operations Research for Health Care 1 (2012)

8. Gürler, Ü., Özkaya, B.Y.: Analysis of the (s, S) policy for perishables with a random shelf life. IIE Transactions 40(8), 759-781 (2008)

9. Hariga, M.: A The Inventory Replenishment Problem with a Linear Trend In Demand, vol. 24(2). Pergamon Press Ltd., Saudi Arabia (1993)

10. Khouja, M.: A Note on the Newsboy Problem with an Emergency Supply Option. Journal of the Operational Research Society 47, 1530-1534 (1996) 
11. Khouja, M.: The single-period (news-vendor) problem: literature review and suggestions for future research. The International Journal of Management Science 27, 537-553 (1999)

12. Minner, S., Transchel, S.: Periodic Review Inventory-Control for Perishable Products under Service-level Constraints. OR Spectrum 32(4), 979-996 (2010)

13. Moon, I., Choi, S.: The Distribution Free Newsboy Problem with Balking. Operation Research Society 46(4), 537-542 (1995)

14. Nahmias, S.: Optimal Ordering Policies for Perishable Inventory-II. Operation Research 23(4) (1975)

15. Nahmias, S.: Perishable Inventory Theory: A Review. The Univeristy of Santa Clara, California (1982)

16. Olsson, F., Tydesjö, P.: Inventory problems with perishable items: Fixed lifetimes and backlogging. European Journal of Operational Research 202, 131-137 (2010)

17. Pierskalla, W.P., Roach, C.D.: Optimal Issuing Policies for Perishable Inventory. Informs 18(11) (1972)

18. Perego, A., Perotti, S., Mangiaracina, R.: ICT for logistics and freight transportation: a literature review and research agen. International Journal of Physical Distribution \& Logistics Management 41(5), 457-483 (2011) 